\title{
Ventilatory efficiency in athletes, asthma and obesity
}

\author{
Sophie É. Collins $\mathbb{1}^{1,2}$, Devin B. Phillips ${ }^{3}$, Andrew R. Brotto ${ }^{1}$, Zahrah H. Rampuri ${ }^{1,2}$ and \\ Michael K. Stickland ${ }^{1,4}$
}

\author{
Number 5 in the Series "Ventilatory efficiency and its clinical prognostic value in cardiorespiratory \\ disorders" \\ Edited by Pierantonio Laveneziana and Paolo Palange
}

${ }^{1}$ Division of Pulmonary Medicine, Faculty of Medicine and Dentistry, University of Alberta, Edmonton, Canada. ${ }^{2}$ Faculty of Rehabilitation Medicine, University of Alberta, Edmonton, Canada. ${ }^{3}$ Respiratory Investigation Unit, Department of Medicine, Queen's University, Kingston, Canada. ${ }^{4}$ G.F. MacDonald Centre for Lung Health, Covenant Health, Edmonton, Canada.

Corresponding author: Michael Stickland (michael.stickland@ualberta.ca)

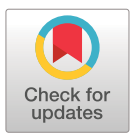

Copyright (CERS 2021.

This article is open access and distributed under the terms of the Creative Commons Attribution Non-Commercial Licence 4.0.

Received: 30 June 2020 Accepted: 16 Sept 2020

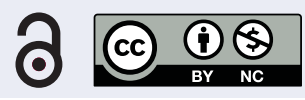

Shareable abstract (@ERSpublications)

The minute ventilation/ $\mathrm{CO}_{2}$ production ratio is useful when evaluating exercise responses. This review describes the physiology of the minute ventilation $/ \mathrm{CO}_{2}$ production ratio and the ratio response in endurance athletes, asthma and obesity. https://bit.ly/3mFdr81

Cite this article as: Collins SÉ, Phillips DB, Brotto AR, et al. Ventilatory efficiency in athletes, asthma and obesity. Eur Respir Rev 2021; 30: 200206 [DOI: 10.1183/16000617.0206-2020].

\section{Abstract}

During submaximal exercise, minute ventilation $\left(V_{\mathrm{E}}^{\prime}\right)$ increases in proportion to metabolic rate (i.e. carbon dioxide production $\left(V^{\prime} \mathrm{CO}_{2}\right)$ ) to maintain arterial blood gas homeostasis. The ratio $V_{\mathrm{E}}^{\prime} / V^{\prime} \mathrm{CO}_{2}$, commonly termed ventilatory efficiency, is a useful tool to evaluate exercise responses in healthy individuals and patients with chronic disease. Emerging research has shown abnormal ventilatory responses to exercise (either elevated or blunted $V^{\prime}{ }_{E} / V^{\prime} \mathrm{CO}_{2}$ ) in some chronic respiratory and cardiovascular conditions. This review will briefly provide an overview of the physiology of ventilatory efficiency, before describing the ventilatory responses to exercise in healthy trained endurance athletes, patients with asthma, and patients with obesity. During submaximal exercise, the $V^{\prime}{ }_{E} / V^{\prime} \mathrm{CO}_{2}$ response is generally normal in endurancetrained individuals, patients with asthma and patients with obesity. However, in endurance-trained individuals, asthmatics who demonstrate exercise induced-bronchoconstriction, and morbidly obese individuals, the $V^{\prime}{ }_{\mathrm{E}} / V^{\prime} \mathrm{CO}_{2}$ can be blunted at maximal exercise, likely because of mechanical ventilatory constraint.

\section{Introduction}

During submaximal exercise, minute ventilation $\left(V_{\mathrm{E}}^{\prime}\right)$ increases in proportion to metabolic rate (i.e. oxygen consumption $\left(V^{\prime} \mathrm{O}_{2}\right)$; and carbon dioxide production $\left(V_{\mathrm{CO}_{2}}^{\prime}\right)$ ) to maintain arterial blood gas and acid-base balance. The response of $V_{\mathrm{E}}^{\prime}$ relative to $V_{\mathrm{CO}_{2}}^{\prime}\left(V_{\mathrm{E}}^{\prime} / V^{\prime} \mathrm{CO}_{2}\right)$ during exercise is said to reflect ventilatory efficiency [1]. Examining the $V^{\prime}{ }_{E} / V^{\prime}{ }_{\mathrm{CO}_{2}}$ relationship during exercise has become a common tool to evaluate exercise responses in patients with respiratory or cardiovascular abnormalities. Further, ventilatory inefficiency (i.e. high $V_{\mathrm{E}}^{\prime} / V^{\prime} \mathrm{CO}_{2}$ ) can help to explain why some individuals with normal lung function present with abnormally high dyspnoea upon exertion [2]. While the $V_{\mathrm{E}}^{\prime}$ relative to $V_{\mathrm{O}_{2}}^{\prime}$ response has also demonstrated prognostic value in various disease states [3-5], the $V^{\prime}{ }_{\mathrm{E}}-V^{\prime} \mathrm{CO}_{2}$ response has been shown to have superior prognostic value $[3,6]$. Further, $V_{\mathrm{E}}^{\prime} / V_{\mathrm{CO}_{2}}^{\prime}$ shows less variability than $V_{\mathrm{E}^{\prime}}^{\prime} / V_{\mathrm{O}_{2}}^{\prime}$ during moderate intensity exercise, due to the tight control of ventilation relative to the arterial partial pressure of $\mathrm{CO}_{2}$ [7-10], and therefore $V_{\mathrm{E}}^{\prime} / V^{\prime} \mathrm{CO}_{2}$ is typically the preferred variable to evaluate ventilation relative to metabolic demand. This review will briefly provide an overview of the physiology and clinical utility of $V_{E}^{\prime} / V^{\prime} \mathrm{CO}_{2}$, before describing the ventilatory responses to exercise in healthy trained endurance athletes, patients with asthma, and patients with obesity. 
Pulmonary gas exchange and ventilatory efficiency

Alveolar ventilation $\left(V_{A}^{\prime}\right)$ is defined as the ventilation which takes part in gas exchange. The relationship between $V^{\prime}{ }_{A}, V^{\prime} \mathrm{CO}_{2}$, and the alveolar partial pressure of $\mathrm{CO}_{2}\left(P_{\mathrm{ACO}_{2}}\right)$ can be described by the following equation [11]:

$$
P_{\mathrm{ACO}_{2}}=\left(V_{\mathrm{CO}_{2}}^{\prime} / V_{\mathrm{A}}^{\prime}\right) \times K
$$

Both $V^{\prime}$ A and $P_{\mathrm{ACO}_{2}}$ are reported under body temperature ambient pressure, saturated (BTPS) with water vapour. $V^{\prime} \mathrm{CO}_{2}$ is reported at $0^{\circ} \mathrm{C}, 760 \mathrm{mmHg}$, standard temperature and pressure dry (STPD). $K$ is a conversion factor (normally $=863$ at sea level and at a normal body temperature of $37^{\circ} \mathrm{C}$ ) used to convert $V^{\prime} \mathrm{CO}_{2}$, from STPD to BTPS [11, 12]. Due to technical limitations, arterial $P_{\mathrm{CO}_{2}}\left(P_{\mathrm{aCO}_{2}}\right)$ is often used as a surrogate for $P_{\mathrm{ACO}_{2}}$. Importantly, all of the $\mathrm{CO}_{2}$ in the expired gas originates from $V_{\mathrm{A}}^{\prime}$, and, assuming complete gas exchange (i.e. negligible ventilation-perfusion mismatch, diffusion limitation and/or shunt), alveolar and arterial $P_{\mathrm{CO}_{2}}$ are equal $\left(P_{\mathrm{ACO}_{2}} \approx P_{\mathrm{aCO}_{2}}\right)$ [13]. While alveolar ventilation is generally well matched to perfusion in healthy individuals with normal lung function $[6,14-16]$, a portion of gas remains in conducting airways and does not participate in gas exchange and is termed anatomical dead space. Further, alveoli that are ventilated but not perfused represent alveolar dead space. The sum of alveolar and anatomical dead space makes up the total dead space ventilation $\left(V_{\mathrm{D}}^{\prime}\right)$, while the total expired minute ventilation $\left(V_{\mathrm{E}}^{\prime}\right)$ is a combination of $V_{\mathrm{A}}^{\prime}$ and $V_{\mathrm{D}}^{\prime}$ and is displayed as:

$$
V_{\mathrm{E}}^{\prime}=V_{\mathrm{A}}^{\prime}+V_{\mathrm{D}}^{\prime}
$$

$V^{\prime}{ }_{E}$ can be measured noninvasively at the mouth with expired gas analysis, while $V_{\mathrm{A}}^{\prime}$ and $V_{\mathrm{D}}^{\prime}$ are more technically difficult to evaluate. If $P_{\mathrm{aCO}}$ is measured by arterial blood gas analysis, then $V_{\mathrm{A}}^{\prime}$ can be determined using equation 1. Additionally, total physiologic dead space as a proportion of tidal volume $\left(V_{\mathrm{D}} / V_{\mathrm{T}}\right)$ can be determined using Enghoff's modified Bohr equation [13, 17]:

$$
V_{\mathrm{D}} / V_{\mathrm{T}}=\left(P_{\mathrm{aCO}_{2}}-P_{\mathrm{ECO}_{2}}\right) /\left(P_{\mathrm{aCO}_{2}}\right)
$$

Where $P_{\mathrm{ECO}_{2}}$ is the mixed expired partial pressure of $\mathrm{CO}_{2}$. The relationship between $P_{\mathrm{aCO}}, V_{\mathrm{E}}^{\prime} / V^{\prime} \mathrm{CO}_{2}$ and $V_{\mathrm{D}} / V_{\mathrm{T}}$ can be described by the modified alveolar ventilation equation:

$$
V_{\mathrm{E}}^{\prime} / V_{\mathrm{CO}_{2}}^{\prime}=K /\left(P_{\mathrm{aCO}_{2}} \times\left(1-\left(V_{\mathrm{D}} / V_{\mathrm{T}}\right)\right)\right.
$$

$K$ is the same conversion factor applied to equation 1, used to convert $V_{\mathrm{CO}_{2}}^{\prime}$ from STPD to BTPS [11, 12].

During exercise, $P_{\mathrm{aCO}_{2}}$ is determined by equation 1 . In practice, individuals often hyperventilate immediately prior to exercise and at low exercise intensities, and therefore $P_{\mathrm{aCO}}$ is often slightly reduced. Once breathing is stabilised, the increase in ventilation is appropriate for metabolic demand and $P_{\mathrm{aCO}}$ remains relatively constant (within $1-3 \mathrm{mmHg}$ of resting values) at submaximal intensities in healthy individuals $[7-10,18]$. To compensate for excessive metabolic acidosis during high intensity exercise, $V^{\prime}$ A increases disproportionately to $V^{\prime} \mathrm{CO}_{2}$ (often termed the respiratory compensation point) [19]. The net effect is a drop in $P_{\mathrm{aCO}}$, below resting values, and an increase in $V^{\prime}{ }_{\mathrm{E}} / V^{\prime} \mathrm{CO}_{2}$. As such, $P_{\mathrm{aCO}}$ typically drops to 30-35 mmHg at maximal exercise, while a $P_{\mathrm{aCO}}$ between $35-38 \mathrm{mmHg}$ at maximal exercise would be suggestive of a borderline effective alveolar hyperventilation, and a $P_{\mathrm{aCO}_{2}}>38 \mathrm{mmHg}$ would be indicative of an inadequate compensatory hyperventilatory response to exercise [20].

In many respiratory and cardiovascular conditions, increased dead space and hyperventilation frequently co-exist. Without direct measurements of $P_{\mathrm{aCO}}$, it can be difficult to quantify the contribution of each to $V_{\mathrm{E}}^{\prime} / V_{\mathrm{CO}_{2}}^{\prime}$. Often, the end-tidal partial pressure of $\mathrm{CO}_{2}\left(P_{\mathrm{ETCO}_{2}}\right)$ is used as a surrogate for $P_{\mathrm{aCO}}$, as it can be easily acquired noninvasively using a breath-by-breath metabolic measurement system. However, multiple studies have shown inaccuracies between arterial blood-gas derived $P_{\mathrm{aCO}}$ and expired gas derived $P_{\mathrm{ETCO}_{2}}$ in patients with pulmonary gas-exchange abnormalities and increased alveolar dead space [21-24]. Therefore, care should be taken when using end-tidal values to infer $P_{\mathrm{aCO}}$ and calculate dead space ventilation.

In various chronic respiratory and cardiovascular conditions, $V_{\mathrm{E}}^{\prime} / V^{\prime} \mathrm{CO}_{2}$ is elevated at rest and throughout exercise compared to healthy individuals. The increased $V^{\prime}{ }_{E} / V^{\prime} \mathrm{CO}_{2}$ is secondary to alveolar hyperventilation (low $P_{\mathrm{aCO}_{2}}$ ) and/or high dead space. The mechanisms for hyperventilation are multifactorial and complex, 
however, increased afferent stimulation from chemoreceptors, ergoreceptors, baroreceptors and pulmonary c-fibres have been identified [25-30]. In some chronic conditions, $V^{\prime}{ }_{E} / V^{\prime} \mathrm{CO}_{2}$ is blunted during exercise, secondary to alveolar hypoventilation (increased $P_{\mathrm{aCO}_{2}}$ ). Alveolar hypoventilation can be secondary to expiratory flow limitation (EFL) and severe ventilatory mechanical constraint [31, 32].

Shortly after the onset of exercise, $V_{\mathrm{D}} / V_{\mathrm{T}}$ falls from values around $0.28-0.35$ to approximately 0.20 in healthy individuals, and stays relatively constant during exercise [33-36]. If total dead space or $V_{\mathrm{D}} / V_{\mathrm{T}}$ is abnormally elevated, the total ventilation must increase to maintain $V^{\prime}$ and $P_{\mathrm{aCO}}$. Following equation 4 , an elevated $V_{\mathrm{D}} / V_{\mathrm{T}}$ (assuming a preserved $P_{\mathrm{aCO}}$ ) would therefore increase $V_{\mathrm{E}}^{\prime} / V^{\prime} \mathrm{CO}_{2}$ [37]. The potential causes for increased dead space include: 1 ) a tachypnoeic breathing pattern (small tidal volume and rapid breathing frequency) [38, 39], 2) increased ventilation-perfusion mismatching, specifically areas of ventilation with no perfusion [40], 3) an increase in the mean ventilation-perfusion ratio (i.e. a rightward shift in the overall relationship) secondary to alveolar hyperventilation and/or impaired cardiac output [41, 42], and 4) intrapulmonary shunt, as $P_{\mathrm{aCO}}$ would increase relative to $P_{\mathrm{ECO}_{2}}$; see equation 3 [40, 43].

Analyzing the $V^{\prime}{ }_{E} / V^{\prime}{ }_{\mathrm{CO}_{2}}$ response to exercise During cardiopulmonary exercise testing, the slope of the $V^{\prime}-V^{\prime} \mathrm{CO}_{2}$ relationship can be determined using linear regression. Typically, the $V_{\mathrm{E}}^{\prime}-V_{\mathrm{CO}_{2}}^{\prime}$ slope is calculated from the start of exercise up to the respiratory compensation point $[6,14,16]$. Minute ventilation rises disproportionally to $V^{\prime} \mathrm{CO}_{2}$ at near-maximal intensities, secondary to excessive metabolic acidosis and respiratory compensation [19], and therefore when data points past the respiratory compensation point are included, the $V_{\mathrm{E}}^{\prime}-V_{\mathrm{CO}_{2}}^{\prime}$ slope can be inflated. In addition to the $V^{\prime}{ }_{E}-V^{\prime} \mathrm{CO}_{2}$ slope, the y-intercept $\left(V_{\mathrm{E}}^{\prime}\right.$ when $\left.V_{\mathrm{CO}_{2}}^{\prime}=0\right)$ of the regression equation can also be reported [44, 45]. The y-intercept is usually small $\left(<3 \mathrm{~L} \cdot \mathrm{min}^{-1}\right)$ in healthy participants [6], and an elevated y-intercept may be suggestive of ventilatory inefficiency. Because of the typical hyperventilation at the start of exercise (see above), the $V_{\mathrm{E}}^{\prime} / V^{\prime} \mathrm{CO}_{2}$ ratio is elevated during light exercise and progressively decreases to its lowest point (nadir $V_{\mathrm{E}}^{\prime} / V^{\prime} \mathrm{CO}_{2}$ ) in tandem with $V_{\mathrm{D}} / V_{\mathrm{T}}$, just prior to the respiratory compensation point $[14,16]$. In most healthy individuals, the $V_{\mathrm{E}}^{\prime} / V^{\prime} \mathrm{CO}_{2}$ ratio at the nadir and anaerobic threshold are often similar [6], and the nadir $V_{E}^{\prime} / V^{\prime} \mathrm{CO}_{2}$ ratio may be of more clinical utility, since the $V_{\mathrm{E}}^{\prime} / V^{\prime} \mathrm{CO}_{2}$ ratio at the anaerobic threshold may not always be identified in clinical populations [46]. Not surprisingly, in healthy individuals at maximal exercise, the $V^{\prime}{ }_{E} / V^{\prime} \mathrm{CO}_{2}$ ratio is higher than the nadir $V_{\mathrm{E}}^{\prime} / V^{\prime} \mathrm{CO}_{2}$ ratio, because of hyperventilation secondary to excessive metabolic acidosis (figure 1).

Sun et al. [6] have created prediction equations for the nadir $V^{\prime}{ }_{\mathrm{E}} / V^{\prime} \mathrm{CO}_{2}$ ratio and $V^{\prime}{ }_{\mathrm{E}}-V^{\prime} \mathrm{CO}_{2}$ slope based on participant age (in years), sex (nadir only) and height (in $\mathrm{cm}$ ):

$$
\begin{gathered}
\text { Nadir } V_{\mathrm{E}}^{\prime} / V_{\mathrm{CO}_{2}}^{\prime}=27.94+0.108 \text { (age) }+0.97 \text { (if female) }-0.0376 \text { (height) } \\
V_{\mathrm{E}}^{\prime}-V_{\mathrm{CO}_{2}}^{\prime} \text { slope }=34.38+0.082 \text { (age) }-0.0723 \text { (height) }
\end{gathered}
$$

As demonstrated in these equations, $V_{E}^{\prime} / V^{\prime} \mathrm{CO}_{2}$ (slope and nadir) increases progressively with age, and the nadir $V_{\mathrm{E}}^{\prime} / V_{\mathrm{CO}_{2}}^{\prime}$ is slightly higher in females than in males [6]. These equations can be helpful in determining the normal response to exercise, and therefore were used in figure 1 to demonstrate the normal nadir $V_{\mathrm{E}}^{\prime} / V_{\mathrm{CO}_{2}}^{\prime}$ ratio and $V_{\mathrm{E}}^{\prime}-V_{\mathrm{CO}_{2}}^{\prime}$ slope response to exercise. Within the manuscript text, these reference equations were also used to evaluate the response in endurance-trained athletes, as well as in participants with asthma or obesity when normative control groups were not presented for comparison.

Ventilatory efficiency in endurance trained athletes

Endurance trained athletes typically achieve a maximum rate of oxygen consumption $\left(V^{\prime} \mathrm{O}_{2} \max \right)$ that is 50-100\% greater than normally active young healthy individuals [47], and as such the requirement for $\mathrm{CO}_{2}$ clearance can become challenging [48]. To enable $\mathrm{CO}_{2}$ clearance at high absolute metabolic rates, endurance athletes must achieve higher ventilation rates than healthy individuals of moderate fitness. In endurance trained athletes during submaximal exercise, ventilation is sufficient to maintain $P_{\mathrm{aCO}}$ and acidbase balance. However, some endurance trained athletes may demonstrate a ventilatory limitation at maximal exercise intensities, which could lead to inadequate compensatory hyperventilation and blunt the $V_{\mathrm{E}}^{\prime} / V^{\prime} \mathrm{CO}_{2}$ response [49-53].

\section{Ventilatory responses to submaximal exercise}

As endurance-trained athletes have superior cardiovascular conditioning, they typically demonstrate lower $V_{E}^{\prime}$ at a given submaximal work rate when compared to untrained individuals due to less reliance on anaerobic metabolism [54, 55]. However, these between-group (trained versus untrained) differences 

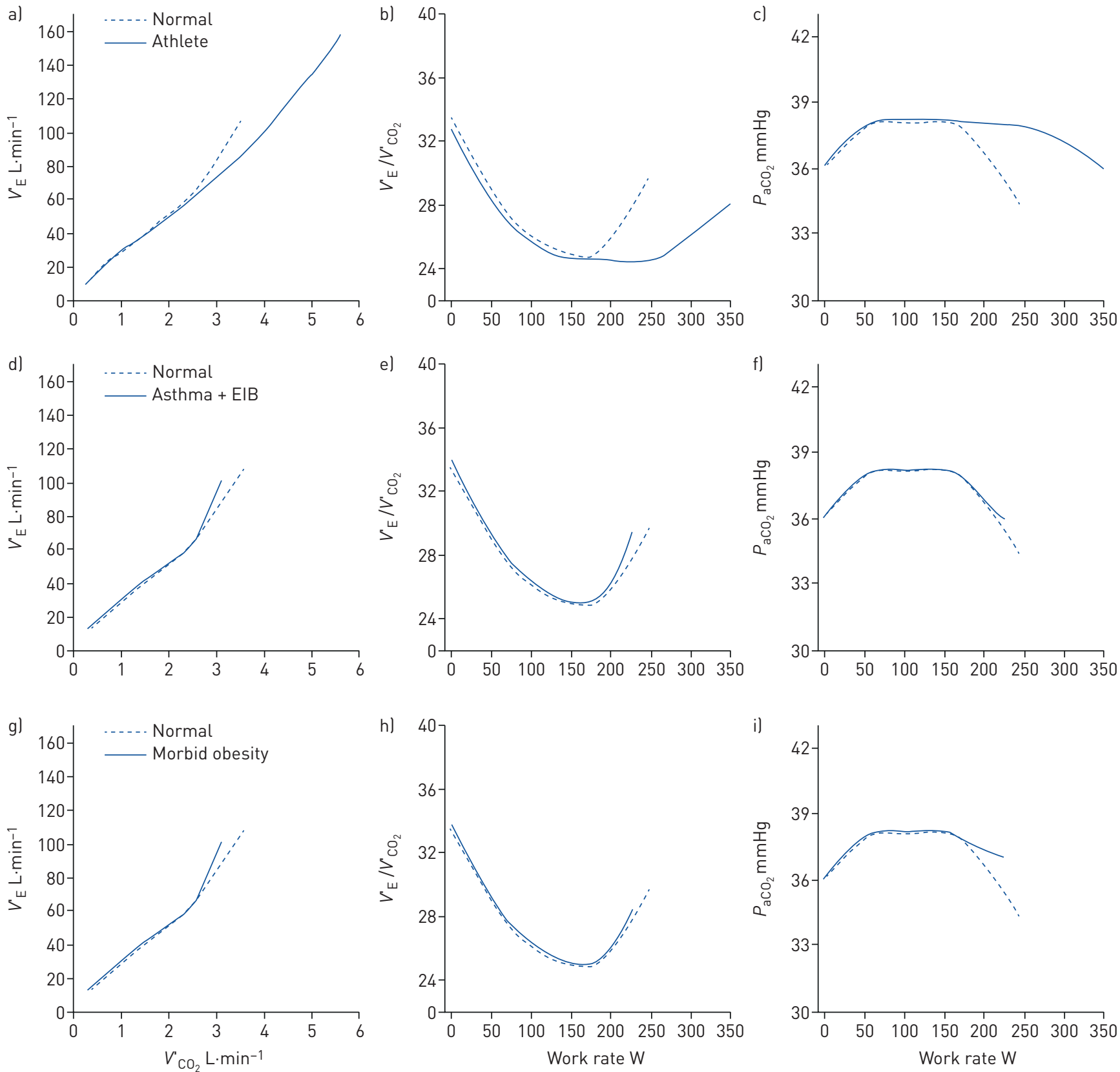

FIGURE 1 Representative ventilatory and gas exchange responses to incremental exercise in a-c) an endurance trained athlete, $d-f$ ) an asthmatic with exercise induced bronchoconstriction and g-i) an individual with morbid obesity, when compared to a healthy individual of average aerobic fitness. EIB: exercise-induced bronchoconstriction; $V_{\mathrm{E}}^{\prime}$ : minute ventilation; $V_{\mathrm{CO}_{2}^{\prime}}$ : carbon dioxide production; $V_{\mathrm{E}}^{\prime} / V^{\prime} \mathrm{CO}_{2}$ : ventilatory equivalent for carbon dioxide production; $P_{\mathrm{acO}}$ : arterial partial pressure of carbon dioxide.

disappear when $V_{E}^{\prime}$ is normalised to metabolic rate (figure 1). Multiple studies have demonstrated no difference in $V_{\mathrm{E}}^{\prime} / V^{\prime} \mathrm{CO}_{2}$ in moderate-to-highly endurance trained male athletes $\left(V_{\mathrm{O}_{2} \max }^{\prime} 55\right.$ $70 \mathrm{~mL} \cdot \mathrm{kg}^{-1} \cdot \mathrm{min}^{-1}$ ) during submaximal exercise, when compared to individuals with normal to low aerobic fitness $\left(V_{\mathrm{O}_{2} \max }^{\prime} \sim 40 \mathrm{~mL} \cdot \mathrm{kg}^{-1} \cdot \mathrm{min}^{-1}\right.$ ) [56-59], or predicted values [6]. To our knowledge, there are no studies that compare $V_{\mathrm{E}}^{\prime} / V^{\prime} \mathrm{CO}_{2}$ slope, nadir and y-intercept values between trained and untrained individuals. Therefore, we analysed unpublished data from our laboratory, and found that the $V_{\mathrm{E}}^{\prime} / V^{\prime} \mathrm{CO}_{2}$ slope, nadir and y-intercept were similar between 16 endurance trained $\left(V_{\mathrm{O}_{2} \max }^{\prime} 67 \pm 7 \mathrm{~mL} \cdot \mathrm{kg}^{-1} \cdot \mathrm{min}^{-1}\right)$ and 16 untrained $\left(V^{\prime} \mathrm{O}_{2} \max 43 \pm 4 \mathrm{~mL} \cdot \mathrm{kg}^{-1} \cdot \mathrm{min}^{-1}\right)$ age- and sex-matched healthy individuals (table 1$)$. Although there are limited data directly comparing arterial blood gas derived parameters in trained versus untrained 
TABLE 1 General ventilatory and pulmonary gas exchange responses to submaximal and maximal exercise in endurance trained athletes, asthmatics and obese when compared to normative values

\begin{tabular}{|c|c|c|c|c|c|}
\hline \multirow[t]{2}{*}{ Variable } & \multicolumn{2}{|c|}{$\begin{array}{l}\text { Elite endurance } \\
\text { trained athlete }\end{array}$} & \multirow[t]{2}{*}{ Asthmatic } & \multicolumn{2}{|c|}{ Obese } \\
\hline & Male & Female & & BMI $30-40 \mathrm{~kg} \cdot \mathrm{m}^{-2}$ & $\mathrm{BMI}>40 \mathrm{~kg} \cdot \mathrm{m}^{-2}$ \\
\hline \multicolumn{6}{|l|}{ Submaximal exercise } \\
\hline$V_{E}^{\prime} / V_{\mathrm{CO}_{2}}$ nadir & $\leftrightarrow$ & $\leftrightarrow$ & N/A & $\mathrm{N} / \mathrm{A}$ & $\mathrm{N} / \mathrm{A}$ \\
\hline$V_{\mathrm{E}}^{\prime} / V_{\mathrm{CO}_{2}}^{\prime}$ y-intercept & $\leftrightarrow$ & $\leftrightarrow$ & $\mathrm{N} / \mathrm{A}$ & $\mathrm{N} / \mathrm{A}$ & $\mathrm{N} / \mathrm{A}$ \\
\hline$V_{E}^{\prime}$-to- $V^{\prime}{ }_{\mathrm{CO}_{2}}$ slope & $\leftrightarrow$ & $\leftrightarrow$ & $\mathrm{N} / \mathrm{A}$ & $\leftrightarrow$ & $\leftrightarrow$ \\
\hline$V_{\mathrm{D}} / V_{\mathrm{T}}$ & $\leftrightarrow$ & $\leftrightarrow$ & $\leftrightarrow$ & $\leftrightarrow$ & $\leftrightarrow$ \\
\hline$P_{\mathrm{aCO}_{2}}$ & $\leftrightarrow$ & $\leftrightarrow$ & $\leftrightarrow$ & $\leftrightarrow$ & $\leftrightarrow$ \\
\hline \multicolumn{6}{|l|}{ Maximal exercise } \\
\hline$V^{\prime}{ }_{E} / V^{\prime} \mathrm{CO}_{2}$ peak & $\downarrow$ & $\downarrow$ & $\leftrightarrow$ or $\downarrow$ & $\leftrightarrow$ & $\downarrow$ \\
\hline$V_{\mathrm{D}} / V_{\mathrm{T}}$ & $\leftrightarrow$ & $\leftrightarrow$ & $\leftrightarrow$ & $\leftrightarrow$ & $\leftrightarrow$ \\
\hline $\mathrm{PaCO}_{2}$ & $\uparrow$ & $\uparrow$ & $\leftrightarrow$ or $\uparrow$ & $\leftrightarrow$ & $\uparrow$ \\
\hline \multicolumn{6}{|c|}{$\begin{array}{l}V^{\prime}{ }_{E}^{\prime} / V^{\prime} \mathrm{CO}_{2} \text { : minute ventilation relative to carbon dioxide production; } V_{\mathrm{D}} / V_{\mathrm{T}} \text { : total physiologic dead space as a } \\
\text { proportion of tidal volume; } P_{\mathrm{acO}} \text { : arterial partial pressure of } \mathrm{CO}_{2} ; \mathrm{N} / \mathrm{A} \text { : not available. The arrows represent the } \\
\text { direction of change compared to age and height matched normative values }[6,20,33-36] \text {. } \leftrightarrow: \text { no difference; } \\
\downarrow: \text { decrease; } \uparrow: \text { increase. }\end{array}$} \\
\hline
\end{tabular}

individuals, previous studies in elite endurance trained athletes with arterial blood sampling have shown that submaximal $P_{\mathrm{aCO}_{2}}$ and $V_{\mathrm{D}} / V_{\mathrm{T}}$ values are similar to values observed in moderately trained healthy individuals [55, 60, 61], and are within normal ranges (table 1) [20, 33-36]. When combined, it is evident that the ventilatory response to submaximal exercise and therefore ventilatory efficiency is not altered by aerobic fitness in young, healthy individuals. Should an abnormal (lower or higher) $V_{E}^{\prime} / V^{\prime} \mathrm{CO}_{2}$ response to submaximal exercise develop, further clinical investigation would be warranted (see the "Pulmonary gas exchange and ventilatory efficiency” section for explanation of potential mechanism(s)).

\section{Ventilatory responses at maximal exercise}

At high metabolic rates, elite endurance trained athletes may exhibit a blunted $V_{\mathrm{E}}^{\prime} / V^{\prime} \mathrm{CO}_{2}$ ratio at maximal exercise intensities [51, 53, 62-65]. Although data are limited, arterial blood gas-derived $V_{\mathrm{D}} / V_{\mathrm{T}}$ values at maximal exercise are generally within normal ranges in endurance trained athletes [53, 64, 66], when compared to normative data (table 1) [33-36]. Some endurance trained athletes demonstrate an inadequate compensatory hyperventilatory response at maximal exercise, as $P_{\mathrm{aCO}}$ fails to drop $<35 \mathrm{mmHg}$ (figure 1) [50, 51, 53]. Importantly, the higher $P_{\mathrm{aCO}}$ typically observed in some endurance trained athletes is not necessarily the result of alveolar hypoventilation per se, but rather an inadequate compensatory hyperventilatory response to excessive metabolic acidosis (table 1) [20, 53].

Several mechanisms for inadequate compensatory hyperventilation in endurance trained individuals are possible. First, respiratory muscle fatigue: multiple studies have shown evidence of respiratory muscle fatigue during heavy exercise in healthy individuals [67-69]. However, experimental data linking respiratory muscle fatigue to inadequate hyperventilation are lacking. Second, altered chemoreflex function: previous work has examined central $\left(V_{\mathrm{E}}^{\prime}\right.$ response to hypercapnia) and peripheral ( $V_{\mathrm{E}}^{\prime}$ response to hypoxia) chemoreceptor function in athletes [53, 61, 63, 70-73]. However, findings are inconsistent, and it is therefore difficult to conclude that a blunted chemoreflex is predictive of an inadequate hyperventilatory response to exercise [20]. Third, mechanical ventilatory constraint: multiple studies have shown evidence of EFL and dynamic mechanical ventilatory constraint at near maximal ventilatory rates in young, trained healthy males and females [53, 62, 74]. Importantly, previous work has shown that when nitrogen is replaced by helium in the inspired gas (i.e. a less dense gas promoting greater airflow), endurance trained athletes achieve a higher $V_{\mathrm{E}}^{\prime}$ and $V_{\mathrm{E}}^{\prime} / V^{\prime} \mathrm{CO}_{2}$, and lower $P_{\mathrm{aCO}_{2}}$ at maximal exercise [64, 75, 76]. These experimental studies support the hypothesis that mechanical ventilatory constraint is a primary cause of inadequate hyperventilation in endurance trained athletes.

Because $V_{\mathrm{E}}^{\prime} / V^{\prime} \mathrm{CO}_{2}$ may be blunted in exceptional athletes at maximal exercise, it may be difficult to distinguish physiological from pathological responses. However, elevated $V^{\prime}{ }_{E} / V^{\prime} \mathrm{CO}_{2}$ responses to either submaximal or maximal exercise would be considered abnormal [6], and in such cases, potential cardiovascular or pulmonary abnormalities should be investigated. 
In summary, the blunted hyperventilatory response to maximal exercise often observed in highly trained endurance athletes is most likely secondary to mechanical ventilatory constraint, although the potential contributions of respiratory muscle fatigue, and central and peripheral chemoreflexes cannot be excluded.

Sex differences in ventilatory efficiency in endurance trained athletes

It has been well documented that young healthy females have an elevated ventilatory response to submaximal exercise $\left(V_{\mathrm{E}}^{\prime} / V^{\prime} \mathrm{CO}_{2}\right.$ nadir, slope and y-intercept) when compared to males [6, 77-80], secondary to increased dead space and alveolar hyperventilation [80-82]. Previous studies have shown that the increased dead space $\left(V_{\mathrm{D}} / V_{\mathrm{T}}\right)$ in females is due to a more rapid and shallow breathing pattern. This breathing response adopted by females has been attributed to a compensatory strategy to minimise the total work of breathing because of smaller lungs [74, 82-84]. It is unclear whether ventilatory responses to submaximal exercise are different in endurance trained female athletes as compared to non endurance-trained females. Elite endurance trained male and female athletes have similar $V_{\mathrm{E}}^{\prime} / V^{\prime} \mathrm{CO}_{2}$ ratios at maximal exercise [49, 62]. Like males, some endurance trained female athletes experience EFL and mechanical ventilatory constraint at heavy exercise intensities, which can result in an inadequate hyperventilatory response (i.e. $P_{\mathrm{aCO}_{2}}>35 \mathrm{mmHg}$ ) and a blunted $V^{\prime}{ }_{\mathrm{E}} / V^{\prime} \mathrm{CO}_{2}$ ratio at maximal exercise [49, 74, 82]. Similar to males, helium inhalation significantly increases the hyperventilatory response (higher $V_{\mathrm{E}}^{\prime}$ and lower $P_{\mathrm{aCO}}$ ) to maximal exercise in females [74]. In summary, these findings suggest that females generally have an elevated $V^{\prime}{ }_{E} / V^{\prime} \mathrm{CO}_{2}$ response to submaximal exercise when compared to males, although it is unclear if differences exist between trained and untrained females.

Ventilatory efficiency in patients with asthma

Asthma is a heterogenous disease characterised by symptoms such as wheezing, coughing, chest tightness and shortness of breath [85], with patients presenting with various degrees of bronchoconstriction, EFL, dynamic hyperinflation and respiratory muscle weakness [86]; all of which can contribute to heightened dyspnoea and exercise intolerance. Some studies have examined people with controlled to partly controlled asthma, who may or may not demonstrate exercise-induced bronchoconstriction (EIB; defined as a $\geqslant 10 \%$ fall in forced expiratory volume in $1 \mathrm{~s}\left(\mathrm{FEV}_{1}\right)$ from baseline following exercise [87]). International guidelines define well controlled asthma as: 1) no or minimal daytime asthma symptoms, 2) no night waking due to asthma symptoms, 3) no activity limitation (including exercise), and 4) no or minimal need for rescue medications [85]. It is common for patients with asthma to experience EIB, with EIB being especially prevalent in uncontrolled asthma [85]. Due to the heterogeneity of asthma, diagnosis can be challenging, especially when symptomatology and objective measures of lung function do not align [85, 88, 89]. This review will focus on studies evaluating patients with clinical symptoms and physiological confirmation of asthma with and without EIB [85].

\section{Ventilatory responses to submaximal exercise}

During submaximal exercise, patients with asthma breathe at a higher operating lung volume and adopt a rapid and shallow breathing pattern [90]. Despite the tachypnoeic breathing pattern, it appears that patients with asthma have a similar $V^{\prime}{ }_{E} / V^{\prime} \mathrm{CO}_{2}$ compared to healthy controls during submaximal exercise (figure 1) [90-95]. Further, $V^{\prime}{ }_{\mathrm{E}} / V^{\prime} \mathrm{CO}_{2}$ in asthmatics is unaffected following an inhaled short-acting $\beta_{2}$-agonist [90]. To our knowledge, there are no studies that report y-intercept, slope or nadir $V_{\mathrm{E}}^{\prime} / V^{\prime} \mathrm{CO}_{2}$ in asthmatics. Importantly, arterial blood gas derived $P_{\mathrm{aCO}}$ and $V_{\mathrm{D}} / V_{\mathrm{T}}$ during submaximal exercise in asthmatics are similar to healthy controls and normative values (table 1) [20,33-36, 96-98]. When combined, it is evident that patients with controlled or partly controlled asthma (with and without EIB) have a normal ventilatory response during submaximal exercise. Therefore, deviation (reduction or increase) in submaximal $V_{\mathrm{E}}^{\prime} / V^{\prime} \mathrm{CO}_{2}$ responses from normal predicted values [6] would warrant further clinical investigation, and may be indicative of comorbid cardiovascular and/or pulmonary vascular abnormalities.

\section{Ventilatory responses at maximal exercise}

Several studies report $V_{E}^{\prime} / V^{\prime} \mathrm{CO}_{2}$ at peak exercise in asthmatics. Many studies have reported a normal $V^{\prime}{ }_{\mathrm{E}} / V^{\prime} \mathrm{CO}_{2}$ response (table 1) [90, 92, 93], while others demonstrated a blunted $V^{\prime}{ }_{\mathrm{E}} / V^{\prime} \mathrm{CO}_{2}$ at peak exercise in asthmatics [98, 99]. Examining the patient characteristics appears to provide information as to why some asthmatics show a blunted $V_{\mathrm{E}}^{\prime} / V^{\prime} \mathrm{CO}_{2}$ response to maximal exercise, while others do not. In looking at the studies showing similar $V_{\mathrm{E}}^{\prime} / V_{\mathrm{CO}_{2}}^{\prime}$ responses to controls, most of the asthmatics in these studies did not demonstrate EIB [90, 92]. In contrast, in the studies demonstrating a blunted $V^{\prime} / V^{\prime} \mathrm{CO}_{2}$ response at peak exercise, most of the patients demonstrated EIB [98], or were categorised by the presence of EIB [99]. Indeed, HaverKamp et al. [99] compared asthmatics with and without EIB, and showed an appropriate hyperventilatory response (i.e. $P_{\mathrm{aCO}_{2}}<35 \mathrm{mmHg}$ at peak) to high intensity constant load exercise in asthmatics without EIB, and an inappropriate hyperventilatory response to exercise in patients with EIB 
(i.e. $P_{\mathrm{aCO}_{2}}>35 \mathrm{mmHg}$ at peak). Combined, these findings suggest that a blunted $V_{\mathrm{E}}^{\prime} / V^{\prime} \mathrm{CO}_{2}$ response to exercise in asthma may be observed in those who demonstrate EIB (table 1 and figure 1).

A number of mechanisms for inadequate hyperventilation in asthmatics are possible including; respiratory muscle fatigue [86, 100, 101], decreased central and/or peripheral chemosensitivity [102-104], and EFL and respiratory mechanical constraint [98, 99, 105]. However, it is likely that respiratory mechanical constraint is the primary cause of inadequate hyperventilation, as previous work has nicely demonstrated that when airflow obstruction is reduced with inhaled corticosteroid therapy, $V_{\mathrm{E}}^{\prime} / V^{\prime} \mathrm{CO}_{2}$ at maximal exercise is increased, $P_{\mathrm{aCO}_{2}}$ reduced, and exercise tolerance improved in asthmatics [106]. Therefore, $V^{\prime}{ }_{\mathrm{E}} / V^{\prime} \mathrm{CO}_{2}$ may be useful in monitoring therapy effectiveness in asthmatics. However, there is currently no indication on how $V^{\prime}{ }_{E} / V^{\prime} \mathrm{CO}_{2}$ pre-treatment may predict post-treatment outcomes.

Importantly, asthma has been shown to be associated with increased cardiovascular morbidity and mortality [107]. Therefore, careful interpretation of the $V_{E}^{\prime} / V^{\prime} \mathrm{CO}_{2}$ response to exercise is encouraged in patients with asthma. While an elevated $V^{\prime}{ }_{E} / V^{\prime} \mathrm{CO}_{2}$ response to submaximal and/or maximal exercise could be due to a dysfunctional breathing pattern (e.g. hyperventilation syndrome [95]), it may be secondary to comorbid cardiovascular and/or pulmonary vascular abnormalities, and additional follow-up should be considered when a high $V_{\mathrm{E}}^{\prime} / V_{\mathrm{CO}_{2}}^{\prime}$ response is observed in asthma.

When combined, it is evident that $V_{\mathrm{E}}^{\prime} / V^{\prime} \mathrm{CO}_{2}$ is similar during submaximal exercise in asthmatics as compared to non-asthmatics. However, $V^{\prime}{ }_{\mathrm{E}} / V^{\prime} \mathrm{CO}_{2}$ at maximal exercise can be blunted in asthmatics, which is likely explained by mechanical ventilatory constraint secondary to EIB.

Ventilatory efficiency in patients with obesity

Based on BMI, individuals with obesity are often classified as mild/class I (30-34.99 $\left.\mathrm{kg} \cdot \mathrm{m}^{-2}\right)$, moderate/ class II $\left(35-39.99 \mathrm{~kg} \cdot \mathrm{m}^{-2}\right)$ and morbid/class III $\left(>40 \mathrm{~kg} \cdot \mathrm{m}^{-2}\right)$ obesity. Exercise limitation is common in patients with obesity and the underlying mechanisms are complex and multifactorial, however, it is widely believed that respiratory abnormalities and elevated dyspnoea are important contributors.

\section{Ventilatory responses to submaximal exercise}

It is well established that ventilation is higher at rest and at any given work rate during incremental exercise in adults with obesity (even mild obesity) when compared to non-obese [108-112]. The increased ventilation in obesity reflects the higher metabolic cost (i.e. $V_{\mathrm{O}_{2}}^{\prime}$ and $V_{\mathrm{CO}_{2}}^{\prime}$ ) of external work, which is primarily due to the increased energy requirement of lifting heavier limbs during weight-supported exercise (i.e. cycling) and, to a greater extent, weight-bearing exercise (i.e. walking) [108, 109, 111, 113, 114]. Additionally, the increased work and oxygen cost of breathing have been identified as potential contributors to the increased metabolic demand at rest and during exercise in obesity [109, 115-117]. Although sub-maximal exercise ventilation is consistently elevated at a given work rate in females and males with obesity compared to non-obese, the between-group differences in ventilation disappear when normalised to metabolic rate (i.e. $V^{\prime}{ }_{\mathrm{E}} / V^{\prime} \mathrm{CO}_{2}$ versus work rate) (figure 1) $[108,118,119]$.

Due to the extra mass loading on the thorax (direct result of extra adipose tissue), patients with obesity have reduced chest wall compliance and breathe at lower lung volumes [108, 120-123]. Further, individuals with obesity generally adopt a rapid and shallow breathing pattern to minimise the work of breathing, especially at higher ventilatory rates [108]. Despite the rapid and shallow breathing pattern, both arterial $P_{\mathrm{CO}_{2}}$ (or $P_{\mathrm{ETCO}_{2}}$ ) and $V_{\mathrm{D}} / V_{\mathrm{T}}$ are generally within normal ranges during submaximal exercise [23, 108, 113, 119, 124]. Further, multiple studies have reported a normal $V_{\mathrm{E}}^{\prime}-V^{\prime} \mathrm{CO}_{2}$ slope, even in morbid obesity, when compared to either non-obese control groups or normative values (table 1 and figure 1) [6, 108, 125-127]. However, one small study [128] in morbidly obese females ( $\left.\mathrm{n}=14, \mathrm{BMI}: 49 \pm 7 \mathrm{~kg} \cdot \mathrm{m}^{-2}\right)$ demonstrated a blunted $V_{\mathrm{E}}^{\prime}-V^{\prime} \mathrm{CO}_{2}$ slope, compared to non-obese controls, which suggests individuals nearing the super-obesity category $\left(\mathrm{BMI}>50 \mathrm{~kg} \cdot \mathrm{m}^{-2}\right)$ may be prone to mechanical ventilatory constraints at submaximal exercise intensities. In general, deviation in submaximal $V_{\mathrm{E}}^{\prime} / V^{\prime} \mathrm{CO}_{2}$ responses from normal predicted values [6] may warrant further clinical investigation in patients with obesity. Specifically, should a patient show a higher than predicted $V^{\prime}{ }_{E} / V^{\prime} \mathrm{CO}_{2}$ response to submaximal exercise, cardiovascular and/or pulmonary abnormalities should be considered.

Ventilatory responses at maximal exercise

Although the $V_{E}^{\prime} / V^{\prime} \mathrm{CO}_{2}$ response during submaximal exercise is relatively preserved in individuals with obesity, the ventilatory response during heavy to maximal exercise is more complex, and greater variability is often observed between different classifications of obesity. To our knowledge, there is no previous work 
using arterial blood gas derived $P_{\mathrm{aCO}}$ during exercise in mild-moderate obesity. A few small studies reporting $P_{\mathrm{ETCO}}$ data would suggest that respiratory mechanical abnormalities do not impair people with mild-moderate obesity, as they generally show a normal hyperventilatory response at maximal exercise $[108,112]$.

Interestingly, in patients with morbid obesity, a divergent ventilatory response at maximal exercise has been identified (table 1 and figure 1). Using arterial blood gas sampling, multiple studies have shown inadequate compensatory hyperventilation (i.e. $P_{\mathrm{aCO}_{2}}$ between $35-38 \mathrm{mmHg}$ ) or an absence of compensatory hyperventilation $\left(P_{\mathrm{aCO}_{2}}>38 \mathrm{mmHg}\right)$ at maximal exercise in males and females with morbid obesity [23, 111, 128-130]. The underlying mechanism(s) for the inadequate and/or absent hyperventilatory response in patients with morbid obesity is not fully understood. However, it is suggested the large amount of fat mass surrounding the chest-wall and diaphragm in patients with morbid obesity results in severe EFL and mechanical ventilatory constraint at high ventilatory rates [108]. The net effect is: 1) an inability to increase alveolar ventilation sufficiently to compensate for the increased metabolic acidosis at heavy exercise and, 2) premature exercise termination. This conclusion is supported by multiple studies demonstrating an increase in peak $V_{\mathrm{E}}^{\prime} / V^{\prime} \mathrm{CO}_{2}$ and reduced $P_{\mathrm{aCO}}$ and/or $P_{\mathrm{ETCO}}$ following bariatric surgery in patients with morbid obesity $[124,130]$. As such, the change in $V^{\prime}{ }_{E} / V^{\prime} \mathrm{CO}_{2}$ observed at peak exercise may be a useful clinical tool when evaluating responses following interventions such as bariatric surgery.

Due to the increasing prevalence of obesity, and the multi-comorbid nature of the disease [131], the authors stress the importance of careful interpretation of ventilatory responses to submaximal exercise in these patients. Furthermore, because other known drivers of ventilation (e.g. elevated physiological dead space, arterial $\mathrm{O}_{2}$ desaturation, altered baseline $P_{\mathrm{aCO}}$, earlier metabolic acidosis) do not appear to be altered in patients with obesity $[108,111,118,119,129,132,133]$, the presence of an elevated $V^{\prime}{ }_{\mathrm{E}} / V^{\prime} \mathrm{CO}_{2}$ response to submaximal exercise is unlikely to be secondary to obesity itself, and may suggest comorbid cardiovascular and/or pulmonary abnormalities.

When combined, the obesity-related research indicates that $V_{\mathrm{E}}^{\prime} / V^{\prime} \mathrm{CO}_{2}$ during submaximal exercise is normal across all classifications of obesity, while $V_{E}^{\prime} / V^{\prime} \mathrm{CO}_{2}$ at maximal exercise appears blunted in patients with morbid obesity secondary to mechanical ventilatory constraint.

Prognostic utility of $V^{\prime}{ }_{\mathrm{E}} / V^{\prime} \mathrm{CO}_{2}$

Although there is evidence that an elevated $V^{\prime}{ }_{E} / V^{\prime} \mathrm{CO}_{2}$ response to exercise is prognostic of mortality in conditions such as chronic heart failure, chronic obstructive pulmonary disease, and pulmonary hypertension [26, 134, 135], it is currently unknown if $V_{\mathrm{E}}^{\prime} / V^{\prime} \mathrm{CO}_{2}$ can be used as a prognostic tool in athletes, asthma or obesity. Further, there is little research demonstrating the prognostic value of a low or blunted $V_{\mathrm{E}}^{\prime} / V^{\prime} \mathrm{CO}_{2}$ response to exercise. However, the $V_{\mathrm{E}}^{\prime} / V^{\prime} \mathrm{CO}_{2}$ response to exercise can be a valuable tool and may help identify abnormal ventilatory responses to exercise or signal the presence of underlying cardiovascular and/or pulmonary disease.

\section{Conclusion}

$\overline{V_{\mathrm{E}}^{\prime} / V^{\prime} \mathrm{CO}_{2}}$ can provide important information to evaluate the ventilatory response to exercise and help to determine underlying mechanism(s) of exercise intolerance. The purpose of this review article was to describe the ventilatory responses to exercise in healthy trained endurance athletes, patients with asthma, and patients with obesity. In summary, moderately trained athletes, asthmatics, and individuals with obesity have normal $V_{E}^{\prime} / V^{\prime} \mathrm{CO}_{2}$ responses to submaximal exercise. Despite representing distinct health and disease states, highly endurance trained athletes, asthmatics with EIB, and individuals with morbid obesity can display inadequate hyperventilatory responses (i.e. blunted $V^{\prime}{ }_{\mathrm{E}} / V^{\prime} \mathrm{CO}_{2}$ ) at maximal exercise secondary to mechanical constraints on ventilation.

Provenance: Commissioned article, peer reviewed.

Previous articles in this series: No. 1: Laveneziana P, Di Paolo M, Palange P. The clinical value of cardiopulmonary exercise testing in the modern era. Eur Respir Rev 2021; 30: 200187. No. 2: Agnostoni P, Sciomer S, Palermo P, et al. Minute ventilation/carbon dioxide production in chronic heart failure. Eur Respir Rev 2021; 30: 200141. No. 3: Watson M, Ionescu MF, Sylvester K, et al. Minute ventilation/carbon dioxide production in patients with dysfunctional breathing. Eur Respir Rev 2021; 30: 200182. No. 4: Ward SA. Ventilation/carbon dioxide output relationships during exercise in health. Eur Respir Rev 2021; 30: 200160. 
Author Contributions: All authors (S.É. Collins, D.B. Phillips, A.R. Brotto, Z.H. Rampuri and M.K. Stickland) contributed to manuscript writing and approved the final version of the manuscript.

Conflict of interest: None declared.

Support statement: Funding was provided from the Canadian Institutes of Health Research, Natural Sciences and Engineering Research Council of Canada and the Lung Association of Alberta and Northwest Territories (M.K. Stickland). S.É. Collins was supported by a Canadian Respiratory Research Network Doctoral Studentship. D.B. Phillips was supported by a postdoctoral fellowship from the Natural Sciences and Engineering Research Council of Canada. Z.H. Rampuri was supported by an Alexander Graham Bell Canada Graduate Scholarship (Masters) from the Natural Sciences and Engineering Research Council of Canada. Funding information for this article has been deposited with the Crossref Funder Registry.

\section{References}

1 Forster HV, Pan LG. Breathing during exercise: demands, regulation, limitations. Adv Exp Med Biol 1988; 227: 257-276.

2 Ross R, Blair SN, Arena R, et al. Importance of assessing cardiorespiratory fitness in clinical practice: a case for fitness as a clinical vital sign: A scientific statement from the American Heart Association. Circulation 2016; 134: e653-e699.

3 Arena R, Myers J, Hsu L, et al. The minute ventilation/carbon dioxide production slope is prognostically superior to the oxygen uptake efficiency slope. J Card Fail 2007; 13: 462-469.

4 Baba R, Nagashima M, Goto M, et al. Oxygen uptake efficiency slope: a new index of cardiorespiratory functional reserve derived from the relation between oxygen uptake and minute ventilation during incremental exercise. J Am Coll Cardiol 1996; 28: 1567-1572.

$5 \quad$ Tang Y, Luo Q, Liu Z, et al. Oxygen uptake efficiency slope predicts poor outcome in patients with idiopathic pulmonary arterial hypertension. J Am Heart Assoc 2017; 6: e005037.

6 Sun XG, Hansen JE, Garatachea N, et al. Ventilatory efficiency during exercise in healthy subjects. Am J Respir Crit Care Med 2002; 166: 1443-1448.

7 Wasserman K, Whipp BJ, Casaburi R. Respiratory control during exercise, eds. In: Comprehensive Physiology. Bethesda, MD, American Physiological Society, 2011; pp. 595-619.

8 Wasserman K, Stringer WW, Sun X-G, et al. Circulatory coupling of external to muscle respiration during exercise. In: Wasserman K, ed. Cardiopulmonary exercise testing and cardiovascular health. Armonk, NY, Futura Pub. Co., 2002; pp. 3-26.

9 Sun X-G, Hansen JE, Hua T, et al. Comparison of exercise cardiac output by the Fick principle using oxygen and carbon dioxide. Chest 2000; 118: 631-640.

10 Stringer WW, Hansen JE, Wasserman K. Cardiac output estimated noninvasively from oxygen uptake during exercise. J Appl Physiol (1985) 1997; 82: 908-912.

11 Rahn H, Fenn WO. A graphical analysis of the respiratory exchange: the O2-CO2 diagram. Washington, D.C., Am Physiol Soc, 1955.

12 Kellogg RH. Laws of physics pertaining to gas exchange. In: Fishman AP, Farhi LE, Tenney SM, et al., eds. Handbook of Physiology, The Respiratory System, Gas Exchange. Bethesda, MD, American Physiological Society, 1987; pp. 13-30.

13 Enghoff $\mathrm{H}$. Volumen inefficax. Bemerkungen zur frage des schadlichen raumes. Uppsala Lakarefoeren Fohr 1938; 44: 191-218.

14 Whipp BJ, Ward SA, Wasserman K. Ventilatory responses to exercise and their control in man. Am Rev Respir Dis 1984; 129: S17-S20.

15 West JB, Dollery CT. Distribution of blood flow and ventilation-perfusion ratio in the lung, measured with radioactive carbon dioxide. J Appl Physiol 1960; 15: 405-410.

16 Whipp BJ, Ward SA. Cardiopulmonary coupling during exercise. J Exp Biol 1982; 100: 175-193.

17 Bohr C. Ueber die lungenatmung. Scand Arch Physiol 1891; 2: 236-268.

18 Forster HV, Pan LG, Funahashi A. Temporal pattern of arterial $\mathrm{CO}_{2}$ partial pressure during exercise in humans. J Appl Physiol (1985) 1986; 60: 653-660.

19 Wasserman K, Hansen JE, Sue DY, et al. Physiology of exercise. Principles of exercise testing and interpretation: including pathophysiology and clinical applications. Fifth edition. ed. Wolters Kluwer Health/ Lippincott Williams \& Wilkins, 2012; pp. 9-61.

20 Dempsey JA, Wagner PD. Exercise-induced arterial hypoxemia. J Appl Physiol (1985) 1999; 87: 1997-2006.

21 Laveneziana P, Webb KA, Wadell K, et al. Does expiratory muscle activity influence dynamic hyperinflation and exertional dyspnea in COPD? Respir Physiol Neurobiol 2014; 199: 24-33. 
Elbehairy AF, Ciavaglia CE, Webb KA, et al. Pulmonary gas exchange abnormalities in mild chronic obstructive pulmonary disease. implications for dyspnea and exercise intolerance. Am J Respir Crit Care Med 2015; 191: 1384-1394.

Bernhardt V, Lorenzo S, Babb TG, et al. Corrected end-tidal $\mathrm{PCO}_{2}$ accurately estimates $\mathrm{PaCO}_{2}$ at rest and during exercise in morbidly obese adults. Chest 2013; 143: 471-477.

Scheidl SJ, Englisch C, Kovacs G, et al. Diagnosis of CTEPH versus IPAH using capillary to end-tidal carbon dioxide gradients. Eur Respir J 2012; 39: 119-124.

Ponikowski P, Chua TP, Piepoli M, et al. Augmented peripheral chemosensitivity as a potential input to baroreflex impairment and autonomic imbalance in chronic heart failure. Circulation 1997; 96: 2586-2594.

Ponikowski P, Chua TP, Anker SD, et al. Peripheral chemoreceptor hypersensitivity: an ominous sign in patients with chronic heart failure. Circulation 2001; 104: 544-549.

Paintal AS. Mechanism of stimulation of type J pulmonary receptors. J Physiol 1969; 203: 511-532.

Paintal AS. Some recent advances in studies on j receptors. In: Kappagoda CT, Kaufman MP, eds. Control of the cardiovascular and respiratory systems in health and disease. New York, Plenum Press, 1995; pp. 15-25.

Scott AC, Francis DP, Davies LC, et al. Contribution of skeletal muscle 'ergoreceptors' in the human leg to respiratory control in chronic heart failure. J Physiol 2000; 529: 863-870.

Farina S, Bruno N, Agalbato $\mathrm{C}$, et al. Physiological insights of exercise hyperventilation in arterial and chronic thromboembolic pulmonary hypertension. Int J Cardiol 2018; 259: 178-182.

Neder JA, Arbex FF, Alencar MC, et al. Exercise ventilatory inefficiency in mild to end-stage COPD. Eur Respir J 2015; 45: 377-387.

O'Donnell DE, Guenette JA, Maltais F, et al. Decline of resting inspiratory capacity in COPD: the impact on breathing pattern, dyspnea, and ventilatory capacity during exercise. Chest 2012; 141: 753-762.

Jones NL, McHardy GJ, Naimark A, et al. Physiological dead space and alveolar-arterial gas pressure differences during exercise. Clin Sci 1966; 31: 19-29.

Wasserman K, Van Kessel AL, Burton GG. Interaction of physiological mechanisms during exercise. J Appl Physiol 1967; 22: 71-85.

Hansen JE, Sue DY, Wasserman K. Predicted values for clinical exercise testing. Am Rev Respir Dis 1984; 129 (2 Pt. 2): S49-S55.

Whipp BJ, Wasserman K. Alveolar-arterial gas tension differences during graded exercise. J Appl Physiol 1969; 27: 361-365.

Mezzani A. Cardiopulmonary exercise testing: Basics of methodology and measurements. Ann Am Thorac Soc 2017; 14, Suppl. 1: S3-S11.

Reindl I, Kleber FX. Exertional hyperpnea in patients with chronic heart failure is a reversible cause of exercise intolerance. Basic Res Cardiol 1996; 91 Suppl 1: 37-43.

Buller NP, Poole-Wilson PA. Mechanism of the increased ventilatory response to exercise in patients with chronic heart failure. Br Heart J 1990; 63: 281-283.

Wagner PD. Causes of a high physiological dead space in critically ill patients. Crit Care 2008; 12: 148.

West JB. Ventilation-perfusion inequality and overall gas exchange in computer models of the lung. Respir Physiol 1969; 7: 88-110.

Robertson HT. Dead space: the physiology of wasted ventilation. Eur Respir J 2015; 45: 1704-1716.

Niklason L, Eckerström J, Jonson B. The influence of venous admixture on alveolar dead space and carbon dioxide exchange in acute respiratory distress syndrome: computer modelling. Crit Care 2008; 12: R53-R53.

Poon C-S, Tin C, Song G. Submissive hypercapnia: why COPD patients are more prone to $\mathrm{CO}_{2}$ retention than heart failure patients. Respir Physiol Neurobiol 2015; 216: 86-93.

Ward SA, Whipp BJ. Ventilatory control during exercise with increased external dead space. J Appl Physiol Respir Environ Exerc Physiol 1980; 48: 225-231.

Agostoni $\mathrm{P}$, Corrà U, Cattadori G, et al. Prognostic value of indeterminable anaerobic threshold in heart failure. Circ Heart Fail 2013; 6: 977-987.

Joyner MJ, Coyle EF. Endurance exercise performance: the physiology of champions. J Physiol 2008; 586: 35-44.

Wasserman K, Casaburi R. Acid-base regulation during exercise in humans. In: Whipp BJ, Wasserman K, eds. Exercise: Pulmonary Physiology and Pathophysiology. 1st ed. Basel, Dekker, 1991; pp. 405-448.

Harms CA, McClaran SR, Nickele GA, et al. Exercise-induced arterial hypoxaemia in healthy young women. J Physiol 1998; 507 (Pt 2)(Pt 2): 619-628.

Caillaud C, Anselme F, Mercier J, et al. Pulmonary gas exchange and breathing pattern during and after exercise in highly trained athletes. Eur J Appl Physiol Occup Physiol 1993; 67: 431-437.

51 Gore CJ, Hahn AG, Scroop GC, et al. Increased arterial desaturation in trained cyclists during maximal exercise at $580 \mathrm{~m}$ altitude. J Appl Physiol (1985) 1996; 80: 2204-2210.

Prefaut C, Anselme F, Caillaud C, et al. Exercise-induced hypoxemia in older athletes. J Appl Physiol (1985) 1994; 76: 120-126. 
Johnson BD, Saupe KW, Dempsey JA. Mechanical constraints on exercise hyperpnea in endurance athletes. J Appl Physiol (1985) 1992; 73: 874-886.

Di Paco A, Dubé B-P, Laveneziana P. Changes in ventilatory response to exercise in trained athletes: Respiratory physiological benefits beyond cardiovascular performance. Arch Bronconeumol 2017; 53: 237-244.

Martin BJ, Sparks KE, Zwillich CW, et al. Low exercise ventilation in endurance athletes. Med Sci Sports 1979; 11: 181-185.

Tedjasaputra V, Bouwsema MM, Stickland MK. Effect of aerobic fitness on capillary blood volume and diffusing membrane capacity responses to exercise. J Physiol 2016; 594: 4359-4370.

Salazar-Martínez E, de Matos TR, Arrans P, et al. Ventilatory efficiency response is unaffected by fitness level, ergometer type, age or body mass index in male athletes. Biol Sport 2018; 35: 393-398.

Mahler DA, Moritz ED, Loke J. Ventilatory responses at rest and during exercise in marathon runners. J App Physiol Respir Environ Exerc Physiol 1982; 52: 388-392.

Salazar-Martínez E, Terrados N, Burtscher M, et al. Ventilatory efficiency and breathing pattern in world-class cyclists: A three-year observational study. Respir Physiol Neurobiol 2016; 229: 17-23.

Sheel AW, Edwards MR, Hunte GS, et al. Influence of inhaled nitric oxide on gas exchange during normoxic and hypoxic exercise in highly trained cyclists. J Appl Physiol (1985) 2001; 90: 926-932.

Martin BJ, Weil JV, Sparks KE, et al. Exercise ventilation correlates positively with ventilatory chemoresponsiveness. J Appl Physiol Respir Environ Exerc Physiol 1978; 45: 557-564.

Guenette JA, Witt JD, McKenzie DC, et al. Respiratory mechanics during exercise in endurance-trained men and women. J Physiol 2007; 581: 1309-1322.

Harms CA, Stager JM. Low chemoresponsiveness and inadequate hyperventilation contribute to exercise-induced hypoxemia. J Appl Physiol (1985) 1995; 79: 575-580.

Dempsey JA, Hanson PG, Henderson KS. Exercise-induced arterial hypoxaemia in healthy human subjects at sea level. J Physiol 1984; 355: 161-175.

Derchak PA, Stager JM, Tanner DA, et al. Expiratory flow limitation confounds ventilatory response during exercise in athletes. Med Sci Sports Exerc 2000; 32: 1873-1879.

Hanson P, Claremont A, Dempsey J, et al. Determinants and consequences of ventilatory responses to competitive endurance running. J Appl Physiol Respir Environ Exerc Physiol 1982; 52: 615-623.

Dempsey JA, Romer L, Rodman J, et al. Consequences of exercise-induced respiratory muscle work. Respir Physiol Neurobiol 2006; 151: 242-250.

Romer LM, Lovering AT, Haverkamp HC, et al. Effect of inspiratory muscle work on peripheral fatigue of locomotor muscles in healthy humans. J Physiol 2006; 571: 4254-4239.

Taylor BJ, Romer LM. Effect of expiratory muscle fatigue on exercise tolerance and locomotor muscle fatigue in healthy humans. J Appl Physiol (1985) 2008; 104: 1442-1451.

Byrne-Quinn E, Weil JV, Sodal IE, et al. Ventilatory control in the athlete. J Appl Physiol 1971; 30: 91-98.

Miyamura M, Yamashina T, Honda Y. Ventilatory responses to $\mathrm{CO}_{2}$ rebreathing at rest and during exercise in untrained subjects and athletes. Jpn J Physiol 1976; 26: 245-254.

Clark JM, Sinclair RD, Lenox JB. Chemical and nonchemical components of ventilation during hypercapnic exercise in man. J Appl Physiol Respir Environ Exerc Physiol 1980; 48: 1065-1076.

Hopkins SR, McKenzie DC. Hypoxic ventilatory response and arterial desaturation during heavy work. J Appl Physiol (1985) 1989; 67: 1119-1124.

Dominelli PB, Foster GE, Dominelli GS, et al. Exercise-induced arterial hypoxaemia and the mechanics of breathing in healthy young women. J Physiol 2013; 591: 3017-3034.

Buono MJ, Maly R. Augmented hyperventilation via normoxic helium breathing does not prevent exercise-induced hypoxemia. Can J Appl Physiol 1996; 21: 264-270.

McClaran S, Wetter T, Pegelow D, et al. Role of expiratory flow limitation in determining lung volumes and ventilation during exercise. J Appl Physiol 1999; 86: 1357-1366.

Olfert IM, Balouch J, Kleinsasser A, et al. Does gender affect human pulmonary gas exchange during exercise? J Physiol 2004; 557: 529-541.

Phillips DB, Ehnes CM, Stickland MK, et al. Ventilatory responses in males and females during graded exercise with and without thoracic load carriage. Eur J Appl Physiol 2019; 119: 441-453.

Ofir D, Laveneziana P, Webb KA, et al. Sex differences in the perceived intensity of breathlessness during exercise with advancing age. J Appl Physiol (1985) 2008; 104: 1583-1593.

Wheatley CM, Snyder EM, Johnson BD, et al. Sex differences in cardiovascular function during submaximal exercise in humans. SpringerPlus 2014; 3: 445.

1 Hopkins SR, Harms CA. Gender and pulmonary gas exchange during exercise. Exerc Sport Sci Rev 2004; 32: 50-56.

McClaran SR, Harms CA, Pegelow DF, et al. Smaller lungs in women affect exercise hyperpnea. J Appl Physiol (1985) 1998; 84: 1872-1881. 
Kilbride E, McLoughlin P, Gallagher CG, et al. Do gender differences exist in the ventilatory response to progressive exercise in males and females of average fitness? Eur J Appl Physiol 2003; 89: 595-602.

Guenette JA, Querido JS, Eves ND, et al. Sex differences in the resistive and elastic work of breathing during exercise in endurance-trained athletes. Am J Physiol Regul Integr Comp Physiol 2009; 297: R166-R175.

Global Initiative for Asthma. Global Strategy for Asthma Management and Prevention; 2020.

Weatherald J, Lougheed MD, Taille C, et al. Mechanisms, measurement and management of exertional dyspnoea in asthma. Eur Respir Rev 2017; 26: 170015.

Parsons JP, Hallstrand TS, Mastronarde JG, et al. An official American Thoracic Society clinical practice guideline: exercise-induced bronchoconstriction. Am J Respir Crit Care Med 2013; 187: 1016-1027.

Lougheed MD, Lemiere C, Dell SD, et al. Canadian Thoracic Society Asthma Management Continuum--2010 Consensus Summary for children six years of age and over, and adults. Can Respir J 2010; 17: 15-24.

Kaplan AG, Balter MS, Bell AD, et al. Diagnosis of asthma in adults. Can Med Assoc J 2009; 10: E210.

Moore LE, Brotto AR, Phillips DB, et al. Exertional dyspnea and operating lung volumes in asthma. J Appl Physiol (1985) 2018; 125: 870-877.

Johnson BD, Scanlon PD, Beck KC. Regulation of ventilatory capacity during exercise in asthmatics. J Appl Physiol (1985) 1995; 79: 892-901.

Cortés-Télles A, Torre-Bouscoulet L, Mejía-Alfaro R, et al. Cardiorespiratory and sensory responses to exercise in well-controlled asthmatics. J Asthma 2015; 52: 576-582.

Rossman MJ, Nader S, Berry D, et al. Effects of altered airway function on exercise ventilation in asthmatic adults. Med Sci Sports Exerc 2014; 46: 1104-1113.

Klansky A, Irvin C, Morrison-Taylor A, et al. No effect of elevated operating lung volumes on airway function during variable workrate exercise in asthmatic humans. J Appl Physiol (1985) 2016; 121: 89-100.

Kinnula VL, Sovijärvi ARA. Hyperventilation during exercise: independence on exercise-induced bronchoconstriction in mild asthma. Respir Med 1996; 90: 145-151.

Forster HV, Dunning MB, Lowry TF, et al. Effect of asthma and ventilatory loading on arterial $\mathrm{PCO}_{2}$ of humans during submaximal exercise. J Appl Physiol (1985) 1993; 75: 1385-1394.

Feisal KA, Fuleihan FJ. Pulmonary gas exchange during exercise in young asthmatic patients. Thorax 1979; 34: 393-396.

Haverkamp HC, Dempsey JA, Miller JD, et al. Gas exchange during exercise in habitually active asthmatic subjects. J Appl Physiol (1985) 2005; 5: 1938.

Haverkamp HC, Dempsey JA, Miller JD, et al. Repeat exercise normalizes the gas-exchange impairment induced by a previous exercise bout in asthmatic subjects. J Appl Physiol (1985) 2005; 99: 1843-1852.

Stell JM, Polkey MI, Rees PJ, et al. Inspiratory muscle strength in acute asthma. Chest 2001; 120: 757-764.

Perez T, Becquart LA, Stach B, et al. Inspiratory muscle strength and endurance in steroid-dependent asthma. Am J Respir Crit Care Med 1996; 153: 610-615.

Magadle R, Berar-Yanay N, Weiner P. The risk of hospitalization and near-fatal asthma in relation to the perception of dyspnea. Chest 2002; 121: 329-333.

Hudgel DW, Weil JV. Depression of hypoxic and hypercapnic ventilatory drives in severe asthma. Chest 1975; 68: 493-497.

Kikuchi Y, Okabe S, Tamura G, et al. Chemosensitivity and perception of dyspnea in patients with a history of near-fatal asthma. N Engl J Med 1994; 330: 1329-1334.

Mediano O, Casitas R, Villasante C, et al. Dynamic hyperinflation in patients with asthma and exercise-induced bronchoconstriction. Ann Allergy Asthma Immunol 2017; 118: 427-432.

Haverkamp HC, Dempsey JA, Pegelow DF, et al. Treatment of airway inflammation improves exercise pulmonary gas exchange and performance in asthmatic subjects. J Allergy Clin Immunol 2007; 120: 39-47. Iribarren C, Tolstykh IV, Eisner MD, et al. Are patients with asthma at increased risk of coronary heart disease? Commentary: cardiovascular disease. Int J Epidemiol 2004; 33: 743-750.

Ofir D, Laveneziana P, Webb KA, et al. Ventilatory and perceptual responses to cycle exercise in obese women. J Appl Physiol (1985) 2007; 6: 2217.

Lafortuna CL, Agosti F, Galli R, et al. The energetic and cardiovascular response to treadmill walking and cycle ergometer exercise in obese women. Eur J Appl Physiol 2008; 103: 707-717.

Babb TG, Delorey DS, Wyrick BL, et al. Mild obesity does not limit change in end-expiratory lung volume during cycling in young women. J Appl Physiol (1985) 2002; 92: 2483-2490.

weight-supported work in obesity. J Appl Physiol 1966; 21: 1815-1820.

2 DeLorey D, Wyrick B, Babb T. Mild-to-moderate obesity: implications for respiratory mechanics at rest and during exercise in young men. Int J Obes (Lond) 2005; 9: 1039.

3 Salvadori A, Fanari P, Tovaglieri I, et al. Ventilation and its control during incremental exercise in obesity. Respiration (Basel) 2008; 1: 26.

Whipp BJ, Davis JA. The ventilatory stress of exercise in obesity. Am Rev Respir Dis 1984; 129: S90-S92. 
115 Kress JP, Pohlman AS, Alverdy J, et al. The impact of morbid obesity on oxygen cost of breathing $\left(\mathrm{VO}_{2 \mathrm{RESP}}\right)$ at rest. Am J Respir Crit Care Med 1999; 3: 883.

116 Lafortuna CL, Proietti M, Agosti F, et al. The energy cost of cycling in young obese women. Eur J Appl Physiol 2006; 97: 16-25.

117 Hulens M, Vansant G, Lysens R, et al. Exercise capacity in lean versus obese women. Scand J Med Sci Sports 2001; 5: 305.

118 Babb TG, Korzick D, Meador M, et al. Ventilatory response of moderately obese women to submaximal exercise. Int J Obes 1991; 1: 59.

119 Balmain BN, Weinstein K, Bernhardt V, et al. Multidimensional aspects of dyspnea in obese patients referred for cardiopulmonary exercise testing. Respir Physiol Neurobiol 2020; 274: 103365.

120 Pelosi P, Croci M, Ravagnan I, et al. The effects of body mass on lung volumes, respiratory mechanics, and gas exchange during general anesthesia. Anesth Analg 1998; 87: 654-660.

121 Jones RL, Nzekwu MM. The effects of body mass index on lung volumes. Chest 2006; 130: 827-833.

122 Sharp JT, Henry JP, Sweany SK, et al. The total work of breathing in normal and obese men. J Clin Invest 1964; 43: 728-739.

123 Babb TG, Ranasinghe KG, Comeau LA, et al. Dyspnea on exertion in obese women: association with an increased oxygen cost of breathing. Am J Respir Crit Care Med 2008; 178: 116-123.

124 Mainra A, Abdallah SJ, Reid RER, et al. Effect of weight loss via bariatric surgery for class III obesity on exertional breathlessness. Respir Physiol Neurobiol 2019; 266: 130-137.

125 de Jong AT, Gallagher MJ, Sandberg KR, et al. Peak oxygen consumption and the minute ventilation/carbon dioxide production relation slope in morbidly obese men and women: influence of subject effort and body mass index. Prev Cardiol 2008; 2: 100.

126 Keller-Ross ML, Chantigian DP, Evanoff $\mathrm{N}$, et al. $\mathrm{V}_{\mathrm{E}} / \mathrm{VCO}_{2}$ slope in lean and overweight women and its relationship to lean leg mass. Int J Cardiol Heart Vasc 2018; 21: 107-110.

127 Arena R, Myers J, Forman D, et al. Influence of etiology of heart failure on the obesity paradox. Am J Cardiol 2009; 104: 1116-1121.

128 Zavorsky GS, Murias JM, Do Jun KIM, et al. Poor compensatory hyperventilation in morbidly obese women at peak exercise. Respir Physiol Neurobiol 2007; 2: 187.

129 Dempsey JA, Reddan W, Rankin J, et al. Alveolar-arterial gas exchange during muscular work in obesity. J Appl Physiol 1966; 21: 1807-1814.

130 Zavorsky GS, Kim DJ, Christou NV. Compensatory exercise hyperventilation is restored in the morbidly obese after bariatric surgery. Obes Surg 2008; 18: 549-559.

131 Guh DP, Wei Z, Bansback N, et al. The incidence of co-morbidities related to obesity and overweight: a systematic review and meta-analysis. BMC Public Health 2009; 9: 1-20.

132 Zavorsky GS, Hoffman SL. Pulmonary gas exchange in the morbidly obese. Obes Rev 2008; 9: 326-339.

133 O'Donnell DE, O'Donnell CDJ, Webb KA, et al. Respiratory consequences of mild-to-moderate obesity: impact on exercise performance in health and in chronic obstructive pulmonary disease. Pulm Med 2012; 2012: 818925.

134 Wensel R, Francis DP, Meyer FJ, et al. Incremental prognostic value of cardiopulmonary exercise testing and resting haemodynamics in pulmonary arterial hypertension. Int J Cardiol 2013; 167: 1193-1198.

135 Neder JA, Alharbi A, Berton DC, et al. Exercise ventilatory inefficiency adds to lung function in predicting mortality in COPD. COPD 2016; 13: 416-424. 